BIO Web of Conferences 3, 02012 (2014)

DOI: $10.1051 /$ bioconf/ 20140302012

(C) Owned by the authors, published by EDP Sciences, 2014

\title{
Different techniques for reducing alcohol levels in wine: A review
}

\author{
Burcu OZTURK ${ }^{1}$ and Ertan ANLI $^{2}$ \\ ${ }^{1}$ Namık Kemal University Şarköy Vocational School, Wine Production Technology Programme, 59800, Şarköy- \\ Tekirdağ/TURKEY, e-mail: bozturk@nku.edu.tr \\ ${ }^{2}$ Ankara University Engineering Faculty, Food Engineering Department, 06110, Dışkapı-Ankara/TURKEY, e-mail: \\ anli@eng.ankara.edu.tr
}

\begin{abstract}
Both the increasing interest on healthy life and the legal limitations of each country for a specific wine style make the adjustment of the wine alcohol content essential. Especially the increase of the average weather temperature around the world gives rise to the grapes grown into high sugar content and low acidity. The wines produced from such grapes have consequently high alcohol content. High alcohol levels can negatively influence wine aroma balance in conjunction with the consumer acceptance. Furthermore excessive alcohol in wine may increase costs in countries where taxes are levied according to alcohol concentration.

Several techniques have been developed for the reduction of ethanol content in wines with excessive alcohol content. The techniques at issue are applied on different stages of wine making process. Implementation of different viticulture techniques including reducing leaf area, monitoring maturity and aroma profiles, winemaking practices consist of utilisation of enzymes, different yeast strains and post fermentation practices such as distillation, blending and membrane based systems applications form a basis for the adjustment of elevated alcohol levels in wine.

The aim of this review is to provide technical and practical information covering the outstanding techniques that may be used to adjust elevated alcohol concentration in wine and their effect on wine from the point of organoleptic characteristics.
\end{abstract}

Key words: wine, dealcoholisation, sugar reduction, must, sensory perception

\section{Introduction}

Wine is composed of two main ingredients, water (generally over $80 \%$ ) and ethanol (usually over 9\%). Alcohol, the second major component of the wine, is primarily produced by yeasts during alcoholic fermentation. Ethanol in wine is the basic alcohol produced in the course of fermentation. On the other hand ethanol can also be produced by grape cells in the course of carbonic maceration in small amounts $[1,2]$.

In recent years alcohol level in wines exceed on account of various reasons. The most important reason for this is the increasing weather temperatures arising from the global warming. Notwithstanding the fact that warm climates can result in full bodied wines with fruit flavour profiles, hot climates can lead to grapes with higher sugar concentration creating wine with high ethanol concentrations above $15 \% \mathrm{v} / \mathrm{v}$ [3]. In addition to its effect on final alcohol concentration, high temperatures during grape ripening can stimulate faster pulp maturation and increase must total soluble solids and $\mathrm{pH}$. High temperatures during the grape ripening also affect the phenolic maturity and aromatic profile of grape leading to wines which are not well-balanced [4].

Alcohol concentration of wine is important for various reasons. Besides its psychological and physiological effects on health, ethanol is indispensable for the aging, stability and organoleptic properties of wine [1]. The growth of microorganisms is limited with the increasing alcohol content during fermentation. Ethanol influences the types and amounts of aromatic components by impressing the metabolic activity of yeasts. Alcohol in wine also plays an important role in solving aromatic and coloring compounds in wine along with water. When considered according to organoleptic characteristics the presence of alcohol with sugars, acids and phenols (especially tannins) define the balance of wine $[1,2]$. In contrast with that high alcohol content is 
associated with several important outcomes. For instance high alcohol concentrations can mask some aromatic volatile compounds. Ethanol may promote the perception of hotness, body and viscosity of a wine and gives burning sensation in higher concentrations as well [5]. In addition, it also enhances the perception of bitterness while diminishing the astringency of tannins [2]. From the point of consumers, high alcohol content has negative effect on human health and is not appreciated by a great majority of consumers drinking responsibly [6].

Wine production is regulated by different institutions and corporations in every country. Wine labels are supposed to state alcohol concentration of the wines in accordance with the both domestic and export legal requirements [7]. As far as the wine legislation in Turkey is concerned, the alcohol content of wine is limited to 9$15 \% \mathrm{v} / \mathrm{v}[8]$.

These considerations as to high alcohol levels in wines stimulate great attention in improvement of the technologies for reducing alcohol content of wines by conserving organoleptic balance, flavour and high quality. This review discusses various techniques to be used aiming at alcohol reduction in wines. The techniques to achieve moderate alcohol levels fit mainly into four basic groups as viticulture, pre fermentation, fermentation and post fermentation applications.

\section{Viticulture Applications}

Alcohol level of wine is mainly determined by the sugar content of the grapes to be used in wine production. The sugar content of grape increases during ripening and continues to rise in the course of dehydration. Therefore it is important to consider the viticulture practises to control final alcohol concentration of wines $[4,6]$.

A wide range of factors significantly affect sugar accumulation in the grape such as choice of vineyard site, soil composition, irrigation strategy, rootstocks, grape varieties, grape yield and leaf area managements [4]. The most evident strategy among these is lowering grape sugar content by increasing yield. Enhancing the bud load, lowering cluster thinning and choosing a vigorous rootstock may be helpful to increase grape yield. While increasing grape yield, special attention should be paid to limit the potential detrimental effects on grape and wine quality. According to the studies performed by Kliewer and Dokoozlian (2005) it is reported that lowering leaf area/ grape weight ratio (less than 0,8 and $0,5 \mathrm{~m} / \mathrm{kg}$, respectively, for Vertical Shoot Position-VSP trained vines and for vines trained to horizontal or divided canopy) may be useful to reduce the grape sugar accumulation in vineyards having high unitary grape yields [9].

Grape sugar accumulation may be taken under control by basal leaf removal since it has a negative influence on sugar accumulation [10]. Contrary to limiting sugar accumulation, it evidently has a positive effect on phenolic development due to the fact that leaf removal increases rate of enzymatic activity responsible for the synthesis of phenolic compounds [11]. It is reported by Vasconcelos and Koblet (1990) that sugar accumulation in the grapes likely to base on available active leaf surface during the period between veraison and harvest. However, it should be underlined that photosynthetic capacity and photosynthate sinks should be well balanced to prevent grape maturity delays $[12,13]$.

Reducing shoot vigour and getting small berries and clusters rich in phenols may also supposed to be effective in lowering maturity level in terms of sugar concentration with high quality grapes providing low alcohol wines. This strategy requires applying combination of appropriate irrigation management, pruning intensity and new genotypes [14].

Clonal selection is one of the most effective factors concerning the rootstock which manage the vigour of the plant and scion [15]. When the rootstock selections is considered, low to moderate vigour genotypes have been recommended to lower the alcohol levels of wines. As far as studies carried out in Australia aiming at lowering sugar accumulation are concerned, the genotype of Merbien series have been determined effective to stimulate the improvement of the colur and phenolics by almost $20 \%$ in Shiraz grape harvested at maturity level lower by $1,5^{\circ}$ Brix than usual $[4,14]$. According to a research performed in south-west of France, 20 from 60 species were characterized to a range of total soluble solid (TSS) of 11,5 to 26 on 30 days after veraison. It was also recorded that $\mathrm{V}$. Candicans varieties always characterised by the lowest TSS [15].

Soil composition of vineyard is also significant for proper ripening. Acidity and mineral combinations are the determinative factors of soil composition. Magnesium deficiency causes delayed ripening additionally loss of aromatic quality and increased effect of dehydration. Nitrogen is the other mineral that influence photosynthesis. Excessive amount of nitrogen can lead to increased grapevine production, with the result of lower sugar accumulation and decrease in total fruit quality [6].

Selection of vineyard location must be decided in accordance with the mesoclimates proper to specific conditions. For instance the slopes shaded by mountains or having fewer sun exposures should be preferred since they have a tendency to be cooler. Furthermore the fields exposed to some wind are appropriate for controlling the sugar accumulation by lowering the environmental temperature $[6,16]$. Among these strategies moderate leaf removal in fruit zone and/or the choice of training systems for the purpose of protecting grape from direct sun light (like pergola, free cordon, Genova Double Curtain- GDC) can be also taken into account providing the grape yield/ quality balance [4].

Except these methods, "double harvest" technique could be put forward to reduce wine alcohol concentration. Since early grape harvest may lead the wines with organoleptic defects owing to herbaceous character and high acidity levels, early ''green' harvest is found unreasonable. Therefore this technique is based on a sequencing harvest consisting of green and normal maturity harvest. The must of grapes coming from bunch thinning at green harvest performed at veraison is conserved and blended with that of grapes harvested at normal maturity. It is reported that the wines obtained from this technique have lower alcohol and $\mathrm{pH}$ and 
higher titratable acidity with no difference in sensorial quality when compared to the wines obtained from traditional wine making method $[4,17]$.

\section{Pre-fermentation Applications}

Limiting excessive alcohol production prior to fermentation is possible by using various techniques aiming at reduction or alternation of fermentable sugar content and composition of the must $[6,18,19]$. However some applications like dilution of the must are illegal in accordance with the wine regulations in certain countries, it is allowed in the USA [6].

Various membrane filtration techniques have been introduced in wine production at different stages. Ultrafiltration to clarify white wine from must, nanofiltration for sugar concentration and removal, reverse osmosis for the purpose of sugar concentration of must and alcohol removal from wine are the most used membrane filtration methods in wine production $[20,21$, 22]. All membrane processes based on fractionalization of the sample into permeate (passes through the membrane), and retentate (retained in the feed) streams [23]. Among these systems nanofiltration membranes have been utilised to remove sugar from must prior to fermentation. Nanofiltration membranes utilise pressure gradient to transport the grape must through the membrane and separate permeate (must with less sugar) and retentate. According to a study performed by Martin et al. (2010), it is reported that successful results were obtained by using control must and permeate mixture in wine making via two-step nanofiltration. Adequate alcohol reduction (2\%) was achieved with little color and aroma loss. It is suggested that reducing filtration time by increasing membrane area or applied pressure may be helpful for satisfactory sensory quality [24].

In addition to membrane filtration, glucose oxidase (GOX) enzyme treatment of the must is another popular technique for the purpose of reducing alcohol level of wine [25]. Glucose oxidase ( $\beta$-D-glucose:oxygen 1oxidoreductase; EC 1.1.2.3.4) catalase enzyme, catalyzes the oxidation of $\beta$-D-glucose to gluconic acid and hydrogen peroxide. In this reaction molecular oxygen is used as an electron acceptor [26].

The conventional GOX enzyme is purified from various fungal sources mainly genus Aspergillus and Penicillium, of which A. niger is the most commonly used in enzyme production [26, 27]. Since the optimum $\mathrm{pH}$ ranges for GOX from $A$. niger is known within the limit of 3.5-6.5, the low $\mathrm{pH}$ musts is found a limiting factor of GOX performance. Therefore raising the $\mathrm{pH}$ of must via calcium carbonate before GOX treatment has been found effective in time saving and increasing the degree of glucose conversion [25]. A summary of compositions of GOX treated and control wines from deacidified musts of Müller Thurgau, Muscat and Riesling grapes with respect to results of study performed by Pickering et al. is given in Table 1. According to a research performed with synthetic grape juice, the reduction in alcohol levels has been reached to 1 and $1,3 \%$ alcohol at $\mathrm{pH} 3,5$ and $\mathrm{pH} 5$ respectively in aerated $\left(8 \mathrm{mg} / \mathrm{L} \mathrm{O}_{2}\right.$ ) synthetic grape juice by using $30 \mathrm{kU}$ enzyme [28]. Because of gluconic acid produced with the action of GOX, titratable acidy of the musts have been increased with a simultaneous decrease of $\mathrm{pH}$. The aeration time of the must is recommended to be as short as possible with respect to microbial stability, aroma loss (especially fruity aroma) and processing costs $[29,30]$.

Table 1. Composition of Müller-Thurgau and Riesling wines prepared from GOX-treated deacidified juice $[18,29,30]$.

\begin{tabular}{|c|c|c|c|c|c|c|}
\hline Component & & $\begin{array}{l}\text { Dercidified } \\
\text { jucice }\end{array}$ & $\begin{array}{l}\text { GOX-treteded } \\
\text { juice }\end{array}$ & $\begin{array}{l}\text { Control } \\
\text { juice }\end{array}$ & $\begin{array}{l}\text { Decteased } \\
\text { alcohol wine }\end{array}$ & Control wine? \\
\hline \multicolumn{7}{|l|}{ Mille-Thurgan } \\
\hline Ethanol & $\mathrm{W}_{\mathrm{v} / \mathrm{v}}$ & & & & 6.2 & 10.5 \\
\hline Gluoses & gl & 84.7 & 10.7 & 84.7 & $<1.0$ & 4.0 \\
\hline Fructoss & d & 89.8 & 87.2 & 89.8 & $<1.0$ & $<1.0$ \\
\hline Gluconic acid & ol & $<0.3$ & 72.7 & $<0.3$ & 66.7 & 40.3 \\
\hline Tantaic cad & ol & 1.9 & 1.7 & 4.3 & 1.8 & 29 \\
\hline Tinzable cadidy' & ol & 3.2 & 26.7 & 7.1 & 27.8 & 8.1 \\
\hline $\mathrm{pH}$ & & 489 & 299 & 3.25 & 3.65 & 3.13 \\
\hline \multicolumn{7}{|l|}{ Risiling } \\
\hline Ethanol & $\mathrm{W}_{\mathrm{v} / \mathrm{v}}$ & & & & 6.5 & 10.2 \\
\hline Brix & $\cdot$ & & & 18.1 & & \\
\hline Tintatble cadidy' & gl & 2.7 & 227 & 10.8 & 226 & 10.7 \\
\hline pH & & 5.49 & 3.07 & 3.08 & 3.15 & 208 \\
\hline Total Aroonods? & all. & 1.77 & 3.89 & 1.93 & 249 & 1.65 \\
\hline Total hydorycinnamates" & moll & 95,67 & 72.8 & 96.6 & 57.8 & 82.2 \\
\hline$A 420$ & & 0.15 & 0.33 & 0.14 & 0.17 & 0.08 \\
\hline A520 & & 0.028 & 0.075 & 0.033 & 0.030 & 0.017 \\
\hline $\mathrm{Fret} \mathrm{SO}_{2}$ & & & & & 43 & 39 \\
\hline Bound $\mathrm{SO}_{2}$ & & & & & 241 & 170 \\
\hline $\mathrm{Todat} \mathrm{SO}_{2}$ & & & & & 284 & 209 \\
\hline
\end{tabular}

\section{Fermentation Applications}

There is a comprehensive approach on practicing either utilization of divergent yeasts and yeast strains by changing alcohol production metabolism or inhibition of fermentation for the purpose of reducing ethanol yield. The major challenge in alcohol level reduction is redirecting the major part of must sugar towards other byproduct(s), while maintaining redox\& energy homeostasis and wine sensorial balance [31]. Another challange is modifying central carbon metabolism, which has a risk of unpredictable effects on metabolite generation. The critical point to pay attention is maintaining yeast strain performances and avoiding accumulation of metabolites having harmful effect on wine quality $[31,32]$.

Different techniques have been applied like expression of NADH-dependent lactate dehydrogenase in $S$. cerevisiae, or a bacterial NADH oxidase in yeast. Although both techniques reduced alcohol production, the wine quality has been spoiled due to the detrimental by-products like lactic acid, acetaldehyde and some oxidized compounds [31]. Non-genetically modified (non-GM) approach such 
as evolutionary engineering has been practiced thanks to adaptive evolution-AE [31, 33]. AE can be applied by diversion of carbons towards the pentose phosphate (PP) pathway leading to lower availability of carbons for ethanol production by elimination of carbons in the form of $\mathrm{CO}_{2}$ and reduced acetate production and increased ester formation (Fig. 1-A). The other approach in this technique is culturing yeast populations in selective conditions like sulfite at alkaline $\mathrm{Ph}$, under hyperosmotic stress by high osmolority glycerol or in the presence of methylglyoxal over a long period of time (Figure 1-B). Evolutionary engineered yeasts with sugars diverted towards glycerol and 2,3- butanediol have ability to reduce the alcohol content of wine by 0,5 to $1 \% \mathrm{vol} / \mathrm{vol}$ [31].

A

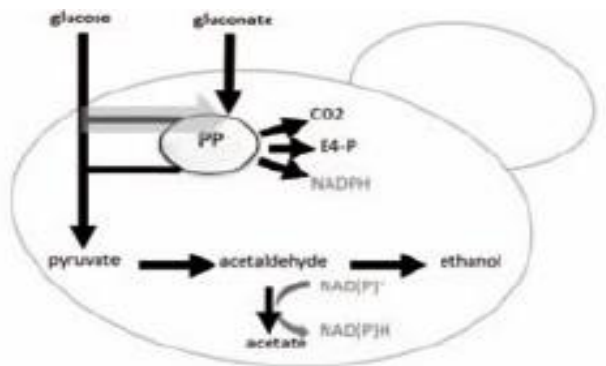

B

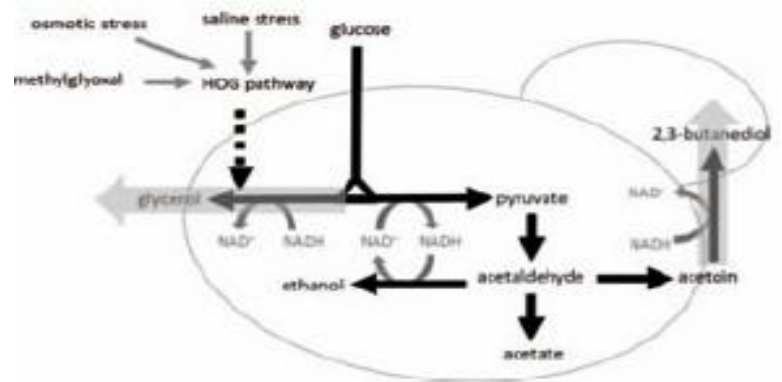

Figure 1. Evolutionary engineering strategies to reduce alcohol yield A: Rerouting carbons towards pentose phosphate pathway by adaptive evolution on gluconate. B: Adaptive evolution under hyperosmotic or salt stress conditions or in the presence of methylglyoxal, to favour glycerol production [31].

Non-Saccharomyces yeast strains have also been proposed for lowering alcohol levels in wine. Yeast strains belonging to other genera, involving Hanseniaspora/Kloeckera, Pichia, Candida or Metschnikowia strains are known to predominate in the first stages of fermentation (up to $\% 5-6$ alcohol content) [32]. Aiming at lowering ethanol production, inoculation of different yeast species that would consume sugars by respiration rather than fermentation and would produce desirable level of secondary metabolites according to the extent of aerobic respiration is considered. Fig. 2 illustrates the expected ideal representation of the sugar consumption and ethanol production profile [34]. According to the above mentioned strategy it is expected that there is a negative correlation between respiratory quotient (RQ) and ethanol reduction [34]. On the basis of this expectation, 63 strains of 29 ascomycetous yeasts were investigated to lower ethanol content of wine thanks to their sugar respiratory catabolism. Respiratory quotient
(RQ) and relevant physiological parameters like the yield of substrate of biomass and key metabolites such as

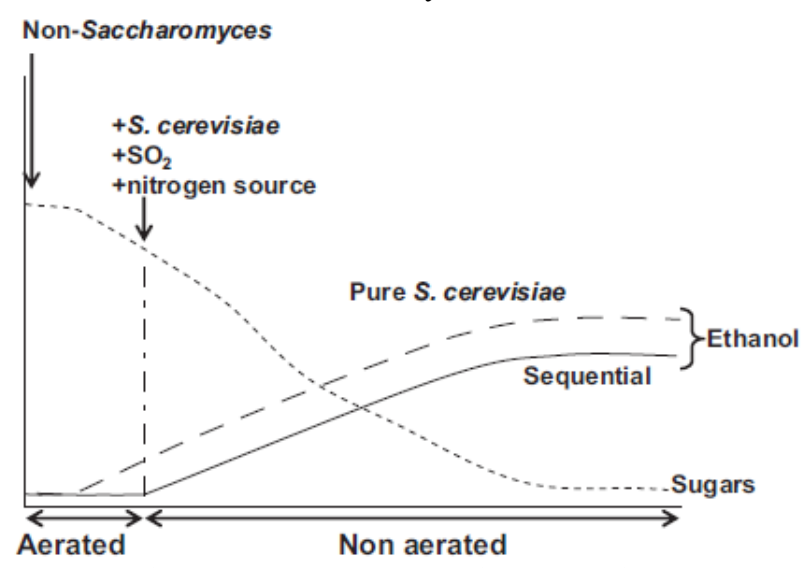

Figure 2. Idealised representation of the expected evolution of ethanol production during must fermentation in sequential inoculation with Crabtree-negative non-Saccharomyces yeast strain followed by S. Cerevisiae at the moment indicated (continous line) and with S. Cerevisiae starter is indicated by (dashed line) [34].

ethanol, glycerol, acetic acid, succinic acid and biomass yield were determined (Table 2). A positive correlation was found for RQ and ethanol yield, acetic acid yield and global sugar consumption, whilst glycerol and biomass yields were negatively correlated to RQ. Physiological characteristics of some strains of Metschnikowia pulcherrima or two species of Kluyveromyces were found suitable for decreasing ethanol yield by respiration with low acetic acid production. With reference to the results from controlled aeration fermentations with one strain of $M$. pulcherrima, it is reported that the so called yeast achieved lowering ethanol yields while preserving must compounds from excessive oxidation [35].

Table 2. Yields on substrate, consumption of sugars, and RQ values obtained for selected yeast strains. Results are expressed as the average \pm standard deviation of two biological replicates

[35].

\begin{tabular}{|c|c|c|c|c|c|c|c|}
\hline Stran & YES (gg) & YCS/gg) & $\operatorname{YsuCS}$ (ngg) & YACES (mgg) & VBMS (gg) & Consumed suger (y) & $\mathbb{R Q}$ \\
\hline Scarviaie EC1118 & $0.5=0.01$ & $0.05=0.01$ & $595 \pm 029$ & $380 \pm 0.0 .5$ & $0.05=001$ & 4806 & $199=0.50$ \\
\hline Sornvisix UDS52 & $0.30=0.01$ & $0003=000$ & $608=0.61$ & $663=0.56$ & $0.03=0.00$ & 6954 & $109=0.00$ \\
\hline C.sode CDS1939 & $0.11=0.01$ & $002 \pm 0000$ & $1156=031$ & $0.48=0.18$ & $022 \pm 0.01$ & 1335 & $1.60=0.02$ \\
\hline C.sdec COSSOCS & $0.18=0.00$ & $0.04=0.00$ & $1234 \pm 022$ & $0.96=0.4$ & $0.07 \pm 0.01$ & 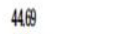 & $231=0.24$ \\
\hline D.fithiffr66 & $001=000$ & $0.11=0.00$ & $290 \pm 0.01$ & $000=000$ & $0.61=002$ & 1085 & $0.97 \pm 0.03$ \\
\hline D.heremi Ho66 & $001=000$ & $0.1=0.01$ & $292 \pm 0.19$ & $0.000=000$ & $0.43=0.01$ & 11.74 & $0.09=0.12$ \\
\hline Kengua DEPVCBSA4 & $0.39=0.00$ & $0.09=0.01$ & $400 \pm 03$ & $680=18$ & $0.05=0.01$ & 3523 & $1.41=0.10$ \\
\hline Klatis AQ21060 & $027=0.00$ & $0.05=0.00$ & $9.67 \pm 009$ & $0.37 \pm 0.06$ & $0.12=0.01$ & 3279 & $0.8=0.04$ \\
\hline Klatismexinus AQII101 & $0.16=0.03$ & $0.06=001$ & $457 \pm 0.49$ & $0.4=0.10$ & $020=000$ & 23.34 & $1.25=0.17$ \\
\hline M. pudterinu IHIF9 & $0 x=000$ & $0.05=0.01$ & $844=307$ & $0.54=0.07$ & $0.15=002$ & 29.78 & $1.0 A=0.13$ \\
\hline M. pudterim IH 1240 & $0.24=003$ & $002=000$ & $1009=1.13$ & $200=0.13$ & $0.097=000$ & 4921 & $1.21 \pm 0.007$ \\
\hline M. pudherinu IH1244 & $0.26=0.00$ & $0.03=0.00$ & $1133=0.18$ & $1.71=0.23$ & $0.10 \pm 0.00$ & 43.19 & $1.26=0.14$ \\
\hline 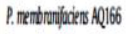 & $0.00=0.00$ & $0.088=0.00$ & $11.44=0.27$ & $0.18=0.25$ & $0.72=0.06$ & 465 & $0.97 \pm 0.13$ \\
\hline 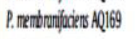 & $000=000$ & $028=000$ & $1.10=0.11$ & $1.80=0.16$ & $0.42=0.11$ & 1386 & $0.99=0.11$ \\
\hline S.sopitsCXX 5776 & $0.11=0.01$ & $0.000=000$ & $7.55 \pm 651$ & $000=0.00$ & $0.69=0.04$ & 685 & $1.05=0.00$ \\
\hline I.dethedia AR216 & $0.03=0.01$ & $0.03=0.00$ & $7.53 \pm 1.02$ & $1.71 \pm 0.08$ & $0.04 \pm 000$ & 6975 & $1.39 \pm 0.16$ \\
\hline I.dellnedi AQ249 & $03=0.02$ & $0.03=0.01$ & $501 \pm 137$ & $418=020$ & $0.04 \pm 000$ & 6975 & $1 . R=0.06$ \\
\hline S.bonticola CESES51 & NA & $\mathrm{NA}$ & NA & NA & $\mathrm{NA}$ & $N A$ & $1.34 \pm 0.065$ \\
\hline S. bombicola CK5911 & NA & $N A$ & $\mathrm{NA}$ & $\mathrm{NA}$ & $N A$ & $\mathrm{NA}$ & $1.84 \pm 0.03$ \\
\hline
\end{tabular}

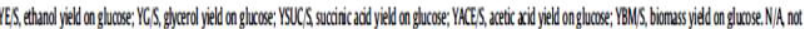

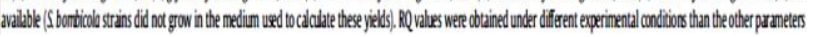

The use of new carbon sinks as metabolic endpoints for sugar-derived carbon may be one approach to achieve 
diversion of carbon flux in fermenting yeast away from ethanol formation [19]. Trehalose-6-phosphate synthase (TPS1) gene, a metabolism mutant, was found as a target for lower ethanol formation when deleted or overexpressed (Fig. 3). Modification of existing yeast pathways was searched and TPS1 and TDH3 were detected as the most promising candidates among 66 yeast deletion mutant for lowering alcohol levels. TDH3, encoding a trehalose- phosphate synthase, was eliminated by further over-expression analysis.

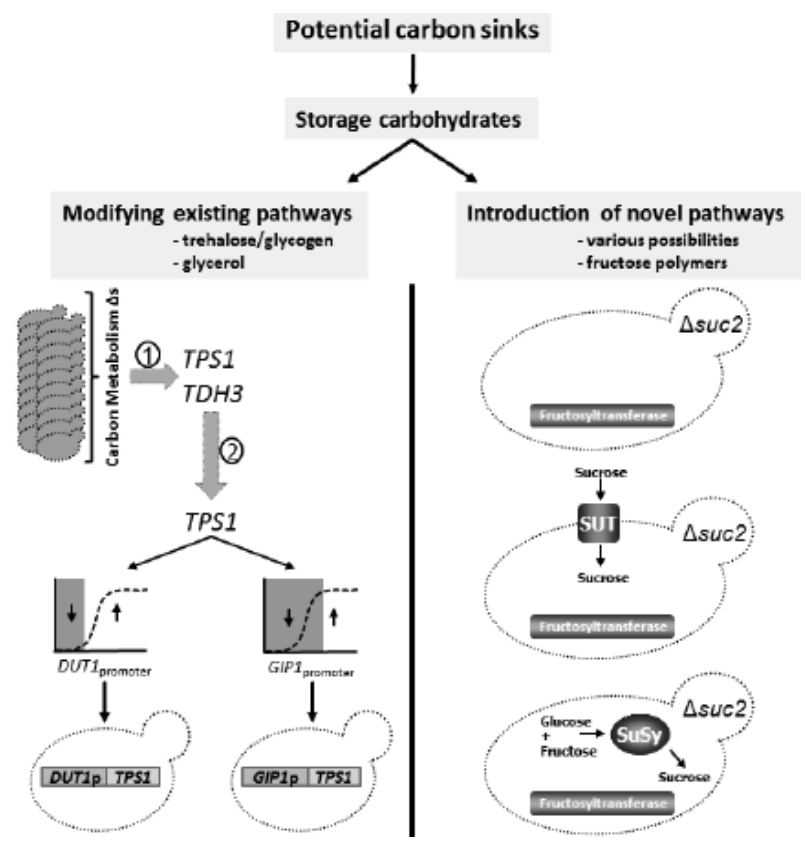

Figure 3. The strategies considering potential carbon sinks as an alternative to ethanol. 1st strategy: the modification of existing yeast pathway.

2 nd strategy: heterologous expression of sugar polymerizing enzymes in order to introduce novel pathways that would divert carbon away from glycolysis. [19].

Expression was changed to be induced either during early exponential or early stationary exponential growth (under the control of the DUT1 promoter and GIP1 promoter, respectively). Heterologous expression of sugar polymerizing enzymes to introduce novel pathways which can divert carbon away from glycolysis is a second strategy in this method. Three separate yeast strains were utilized as base to express bacterial fructosyltransferase (FTF) catalyzing formation of fructose polymers. The base strains which would respectively import and synthesize the FTF substrate sucrose contain an invertase null mutant (suc2 $\Delta$ ), sucrose transporter (SUT) or sucrose synthase (SuSy)(Fig. 3). With the purpose of modifying expression and following trehalose production, TPS 1 was placed under the control two different growth stage specific promoters. It was recorded that ethanol was successfully lowered without important effects on fermentation behavior, or undesirable by-products as a result of the so called modifications [19].

The utilization of metabolic blockers redirecting glycolytic pathway in yeast is another way of limiting ethanol in the course of fermentation stage. Furfural, a well known aromatic aldehyde, was investigated as a metabolic inhibitor for reducing the alcohol content of model wines [36]. It is considered that furfural has a competitive inhibition effect on the enzymes alcohol dehydrogenase and aldehyde dehydrogenase involved in the production of ethanol and acetic acid, respectively [37]. Inhibitory mechanism of furfural on ethanol production during alcoholic fermentation is illustrated in Fig.4 [38]. Satisfactory results have been observed with the utilization of this chemical on the alcohol level reduction. It is reported that reduction of $0,37 \%$ and $0,6 \%$ $\mathrm{v} / \mathrm{v}$ alcohol was achieved without any spoilage of natural aromatic profile after the addition of $10 \mathrm{mg} / \mathrm{L}$ and 50 $\mathrm{mg} / \mathrm{L}$ furfural, when the fermenting yeasts were 7VA and Distinction respectively.

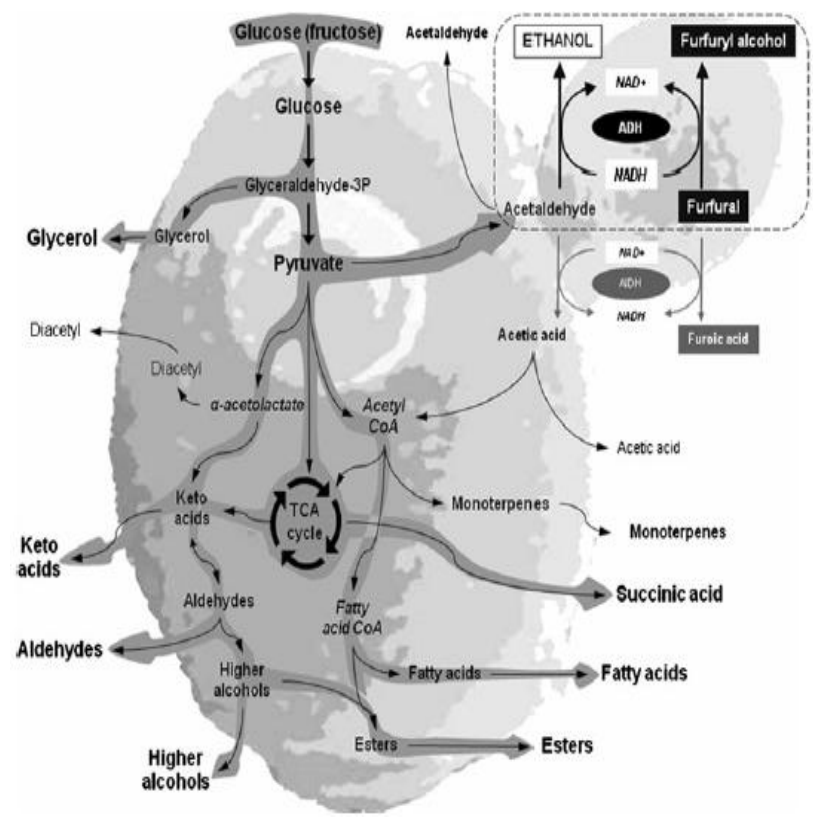

Figure 4. Inhibitor effect of furfural on the production of ethanol during alcoholic fermentation by $S$. Cerevisiae [38].

\section{Post Fermentation Applications}

The removal of ethanol from wine after fermentation can be achieved by using various technologies like membrane filtrations, distillation under vacuum or atmospheric pressure, spinning cone columns, adsorption (on resins, silica gels or zeolite), freeze concentration, evaporation and extraction using organic solvent or supercritical solvent $[39,40]$.

Semi-permeable membranes by which alcohol can be separated from wine have found field of application in winemaking for many years. Especially $0,65 \mu \mathrm{m}$ and 0,45 $\mu \mathrm{m}$ filtration cartridges made from membrane have been used in oenology [41]. Among membrane filtration techniques reverse osmosis (RO) is the most utilized technique for the purpose of reducing the alcohol content of wine with the advantage of working at low temperatures of approximately $5-10^{\circ} \mathrm{C}$ having minimal negative effect on taste. Working principle of RO is pressure filtration (up to $4 \mathrm{MPa}$ ) of wine through a fine porous membrane permeable to water and alcohol. The applied pressure may lead to temperature increase at 
membrane surface. Therefore, heat exchangers are a component of apparatus with operating temperatures around 20 to $22^{\circ} \mathrm{C}$. Since water is removed along with alcohol, it should be added back to the treated wine or added to wine before RO application. Since addition of water to wine is prohibited in many countries, alternatively low-Brix juice can be added to restore the wine to original water content [18, 39]. Although membrane is not permeable to most of the dissolved extract components, some aroma compounds (i.e. esters and aldehydes), organic acids and potassium are able to diffuse together with the alcohol [39]. As far as the research performed by Gil et al. is concerned, the partial dealcoholisation of two red wines of AOC Priorat and Penedès by RO had no significant effect both on chemical composition (except alcohol content) and sensory properties (Table 3 ). RO allows production flexibility with the ability of reducing alcohol content of wine from $12 \%-15 \%$ to less than $0,5 \% \mathrm{v} / \mathrm{v}[18,42]$.

Table 3. Chemical composition of wines subjected to partial dealcoholization by reverse osmosis [42].

\begin{tabular}{ccccccc}
\hline \multirow{2}{*}{ Parameter } & \multicolumn{3}{c}{ AOC Penedès } & \multicolumn{4}{c}{ AOC Priorat } \\
\cline { 2 - 7 } & Control & $-1 \%$ & $-2 \%$ & Control & $-1 \%$ & $-2 \%$ \\
\hline Ethanol content $(\%)$ & $14.8 \pm 0.2 \mathrm{~A}$ & $13.8 \pm 0.2 \mathrm{~B}$ & $12.8 \pm 0.2 \mathrm{C}$ & $16.2 \pm 0.2 \mathrm{~A}$ & $15.1 \pm 0.2 \mathrm{~B}$ & $14.1 \pm 0.1 \mathrm{C}$ \\
Titratable acidity $(g /))$ & $4.8 \pm 0.1 \mathrm{~A}$ & $4.8 \pm 0.1 \mathrm{~A}$ & $4.9 \pm 0.1 \mathrm{~A}$ & $5.2 \pm 0.1 \mathrm{~A}$ & $5.2 \pm 0.1 \mathrm{~A}$ & $5.6 \pm 0.1 \mathrm{~B}$ \\
Color intensity & $15.3 \pm 1.5 \mathrm{~A}$ & $15.6 \pm 0.9 \mathrm{~A}$ & $15.4 \pm 0.7 \mathrm{~A}$ & $15.4 \pm 0.2 \mathrm{~A}$ & $15.2 \pm 0.4 \mathrm{~A}$ & $14.5 \pm 0.5 \mathrm{~A}$ \\
Hue & $67.7 \pm 1.1 \mathrm{~A}$ & $67.9 \pm 0.4 \mathrm{~A}$ & $68.3 \pm 1.5 \mathrm{~A}$ & $59.3 \pm 1.2 \mathrm{~A}$ & $60.0 \pm 0.4 \mathrm{~A}$ & $59.2 \pm 0.5 \mathrm{~A}$ \\
Anthocyanins (mg/l) & $567 \pm 41 \mathrm{~A}$ & $546 \pm 19 \mathrm{~A}$ & $574 \pm 14 \mathrm{~A}$ & $200 \pm 13 \mathrm{~A}$ & $206 \pm 23 \mathrm{~A}$ & $226 \pm 11 \mathrm{~A}$ \\
IPT & $72.9 \pm 2.5 \mathrm{~A}$ & $73.9 \pm 2.3 \mathrm{~A}$ & $75.8 \pm 20.6 \mathrm{~A}$ & $62.4 \pm 0.5 \mathrm{~A}$ & $62.2 \pm 0.2 \mathrm{~A}$ & $62.1 \pm 0.8 \mathrm{~A}$ \\
Proanthocyanidins $(g / /)$ & $1.8 \pm 0.3 \mathrm{~A}$ & $1.6 \pm 0.2 \mathrm{~A}$ & $1.7 \pm 0.2 \mathrm{~A}$ & $1.6 \pm 0.2 \mathrm{~A}$ & $1.7 \pm 0.3 \mathrm{~A}$ & $1.5 \pm 0.2 \mathrm{~A}$ \\
mDP & $6.8 \pm 1.2 \mathrm{~A}$ & $7.5 \pm 1.8 \mathrm{~A}$ & $7.2 \pm 0.6 \mathrm{~A}$ & $6.8 \pm 1.8 \mathrm{~A}$ & $5.8 \pm 0.3 \mathrm{~A}$ & $6.5 \pm 0.7 \mathrm{~A}$ \\
\hline
\end{tabular}

All data are expressed as the average of the three replicates standard deviation $(n=3)$. Statistical analysis: one-factor ANOVA and Scheffe's test (both $p<0.05$ ). Different letters indicate the existence of statistically significant differences.

The spinning cone column (SCC) is another up to date technique employed to alcohol removal from wine. The SCC is a gas-liquid contacting device composed of a vertical shaft rotating nearly $350 \mathrm{rpm}$, supporting up to 22 overturned (pointing downwards) cones. Between each pair of cones a stationary cone is attached to the casing of the column. The equipment is used to extract volatile components from a liquid via centrifugal force of rotation and driving force of gaseous flow. A stripping gas, like nitrogen, is allowed to the base of the column and flows through the voids between rotating and fixed cones. The gas is then gathered at the top of the column and exposed to a significant turbulence. Volatile components can be evaporated with the help of negative pressure applied at low temperatures, so that delicate flavors can be recovered [18, 23, 39]. The removal of wine alcohol by SCC involves 2-step process. The delicate wine aroma compounds (nearly $1 \%$ of total wine) is recovered of the $1^{\text {st }}$ pass of wine at low temperature (around $26-28^{\circ} \mathrm{C}$ ) and vacuum conditions $(0,04 \mathrm{~atm})$. Dearomatized wine is passed in second time aiming at alcohol removal at slightly higher temperatures (around $38^{\circ} \mathrm{C}$ ) and vacuum conditions [43].Ethanol concentration of a wine can be reduced from $15 \%$ to less than $1 \% \mathrm{v} / \mathrm{v}$ by using SCC.
Dealcoholized and dearomatized wine is finally blended with recovered aroma. SCC technique offers minimal thermal damage ensuring aroma conservation, low entrainment, low liquid residence with high efficiency $[18,39]$. On the other hand it requires extra devices like heat exchangers, pumps, condensers and has a high investment cost, which make it a favorable technology for only large wineries [23].

In addition to the above mentioned techniques, alcohol and aroma containing condensate resulting from wine evaporation can be extracted thanks to supercritical liquids. As a food appropriate solvent, $\mathrm{CO}_{2}$ gas is utilized under specific pressure and temperature conditions. With the help of subsequent and differential pressure \& temperature adjustments, ethanol and aroma compounds can be separated after precipitation of extracted wine components [39]. Due to high capital costs, high vacuum requirement and inflexibility of plant, super critical extraction couldn't spread on wine industry. Contrary to all these disadvantages supercritical $\mathrm{CO}_{2}$ extraction doesn't cause any deterioration due to the fact that chemical composition (except ethanol) doesn't denature [44].

\section{Organoleptic Characteristics}

Reduced alcohol wines may show a reduced sensory quality in comparison with original wines with fullstrength on account of flavor imbalance and lack of body. Lowering ethanol content of wine may affect sweetness, palate and balance of wine owing to the sensory characteristics of alcohol. Furthermore reduction of alcohol level decreases intensity of acidity and astringency. The devolution of sensory properties can occur as a result of process losses like volatile aroma compounds, reduction of the volatility of esters and higher alcohols due to absence of alcohol or as a direct outcome of reduced ethanol content [18, 39, 45].

The best results may be observed in consequence of viticulture applications in terms of sensory characteristics of wine, since the wine is not subjected to any process that may cause any color and aroma losses affecting organoleptic characteristics. Nevertheless very little published information is available informing about the sensory evolution of reduced alcohol wines thanks to viticulture strategies, this strategy results in well balanced wines with rich color, aromatic and phenolic compositions when applied in correct combination [42, 46]. Despite all the viticulture techniques applied, it is inevitable that certain vineyards may yield grapes with high sugar content due to climate. That being the case, the other wine making strategies are preferable.

When compared post fermentation methods like permoseparation on RO membrane, dialysis and extraction by subcritical and supercritical $\mathrm{CO}_{2}$ among each other, it is reported that extraction by subcritical and supercritical CO2 was the most promising method [39]. Regarding to another comparison made between nanofiltration and RO techniques, the use of nanofiltration for wine alcohol removal is concluded to 
have some advantages like reduction of volatile acidty and minimum loss of anthocyanins [47].

However it is reported that increased aroma loss and change in flavour components are experienced with extending amount of alcohol removed regardless of which method is used. Therefore the sensory properties and acceptability of alcohol removed wines may differ based on the alcohol concentration [39].

\section{Conclusion}

As a consequence of climate change all over the world, nowadays the winemakers encounter a problem of excessive alcohol content in wine. The combination of health, legal regulations, economy and quality matters related with high alcohol wines has led the winemakers and scientists to develop technologies for reducing alcohol levels that conserve overall quality of the wine. These techniques can be applied in different stages of winemaking process either individually or in combination to achieve high quality wine. Most important factors influencing selection of the technique are minimum quality loss in the final wine and minimum cost for the applied technique. In the light of this information, the novel winemaking techniques are suggested to be practiced and adapted to wine production considering from the point of both producers and consumer perceptions.

\section{References}

1. R. S. Jackson, Chem. Cons. of Gr. and Wine. Wine Science-Third Edition, 270-331 (San Diego: Academic Press, 2008)

2. P. Rib'ereau-Gayon, Y. Glories, A. Maujean, D. Dubourdieu, Alc. and Oth. Vol. Comp. Handbook of Enology Volume 2 The Chemistry of Wine Stabilization and Treatments 2nd Edition, 51-65 (John Wiley\&Sons,Ltd, 2006)

3. P. Godden, Per. Wine Ins. Iss. Australian Grape grower and Winemaker, 443: 10-14 (2000)

4. V. Novello, L. de Palma, Vit. Str. to Red. Alc. Lev. in Wine, ALCOHOL LEVEL REDUCTION IN WINEOENOVITI INTERNATIONAL NETWORK, 3-8 (2013)

5. R. Gawel, S. van Sluyter, E. Waters, Eff. Eth. Gly on Body. Australian Journal of Grape and Wine Research, 13: 38-45(2007)

6. A. Salamon, Tech. to Ach. Mod. Alc. L. in S. Afr. Wine, Assignment submitted in partial requirement for the Cape Wine Master Diploma (2006)

7. R. S. Jackson, 2000. Wine Laws, Auth. and Geo. Wine Science (Second Edition), 482-543 (San Diego: Academic Press, 2000)

8. Turkish Food Codex, Wine Legislation (Legislation Number: 2008/67)

9. W. M. Kliewer, N. K. Dokoozlian, L. area/crop We. Rat. Of Gr: Inf. on Fr. Comp. and Wine Qual.. Am. J. Enol. Vitic., 56: 170-181(2005)
10. I. Korkutal, E. Bahar. Infl. of Diff. Soil Till. and Leaf Rem. Tre. on Yield, Clus. and B. Char. in cv. Syrah (Vitis vinifera L.). Bulgarian Journal of Agricultural Science. 19(4): 652-663 (2013)

11. F. Di Profio, A. G. Reynolds, A. Kasimos, Can. Man. and Enz. Imp. on Mer., C. Fr. and C. Sau. I. Y. and Ber. Com. Amer. J. Enol. Vitic., 62 (2): 139-151 (2011)

12. M. C. Vasconcelos, W. Koblet, 1990. Yie., fr. Qua., bud Fer. And Sta. Res. of the wood as a fun. of leaf rem. in Vit. vin. Ev. of Com. and stres Rec.Vitis, 29: 199-221(1990)

13. F. Di Profio, A. G. Reynolds, A. Kasimos, Can. Man. and Enz. Imp. on Mer., C. Fr. and C. Sau. II. Wine com. and Qua. Amer. J Enol. Vitic., 62 (2): 152-168 (2011)

14. P. R Clingeleffer, Vit. Prac. to Mod. Wine Alc. Cont. Proceedings ASVO Seminar:Towards best practice through innovation in winery processing. Tanunda (SA), Australia, 17 October (2007)

15. L. Bordenave, Z. W. Dai, A. Lusson, N. Ollat, S. Delrot, Vin. Acc. less Sug. ALCOHOL LEVEL REDUCTION IN WINE - OENOVITI INTERNATIONAL NETWORK, 14-20 (2013)

16. R. Smart, M. Robinson, Sunlight into Wine: A Handbook for Winegrape Canopy Management. Winetitles (Adelaide, 1991)

17. F. Martinez de Toda, P. Balda, Dec. Alc. Lev. in Q. red wines by the "d. Har." Tech. Progrès Agricole et Viticole, Proceedings 17th International Symposium GiESCO, Asti - Alba (CN), Italy, 29th August - 2nd September, 463-466 (2011)

18. L. M. Schmidtke, J. W. Blackman, S. O. Agboola, Prod. Tech. for Red. Alc. Wines. Journal of Food Science, 71: Nr. 1 ( 2012)

19. F. F. Bauer, D. Rossouw, J. Franken, Find. Nov. Car. Sinks in S. Cer. ALCOHOL LEVEL REDUCTION IN WINE - OENOVITI INTERNATIONAL NETWORK, 38-46 (2013)

20. A. Versari, R. Ferrarini, G.P. Parpinello, S. Galassi, Con. of gr. Must by Nan. Mem. Trans. IChemE. 81:275-278 (2003)

21. A. Rektor, A. Kozak, G. Vatai, E. Bekassy-Molnar, Pilot pl. RO-fil. of Gr. Jui. Sep. Purif. Technol. 57: 473-475 (2007)

22. J. Labanda, S. Vichi, J. Llorens, E. López-Tamames, Mem. Sep. Tech. for the red. of alc. Deg. of a Wh. M. wine, LWT: Food Sci. Technol. 42: 1390-1395 (2009)

23. B. Saha, P. Torley, J. W. Blackmann, L. M. Schmidtke, Rev. of Pro. Tec. to Red. Alc. Lev. in Wines, ALCOHOL LEVEL REDUCTION IN WINE OENOVITI INTERNATIONAL NETWORK, 78-86 (2013)

24. N. Garcia-Martin, S. P. Magarino, M. O. Heras, C. G., Mihnea, M. L. Gonzales- Sanjose, L. Palacio, P. A. Pradonos, Hernandez, Sug. Red. in Musts with Nan. Seperation and Purification Technology, 76: 158-170 (2010)

25. G. J. Pickering, D. A. Heatherbell, M. F. Barnes, Opt. Gl. Con. in the Pr. of R. Alc. wine u. GOX, Food 
Research International, Vol. 31: No. 10, 685-692 (1998)

26. S. B. Bankar, M. V. Bule, R. S. Singhal, L. Ananthanarayan, Gl. Ox. - An Ov. Biotechnology Advances, 27: 489-501 (2009)

27. S. Pluschkell, K. Hellmuth, U. Rinas, Kin. of GOX Exc. by Rec. A. niger. Biotechnol Bioeng, 51: 215-20 (1996)

28. B. N. E Biyela, W. J. du Toit, B. Divol, D. F. Malherbe, P. van Rensburg, The pr. of r.-alc. wines using Glu. Mono® 10.000 BG-tr. gr. j. S. Afr. J. Enol. Vitic., Vol. 30 : No. 2 (2009)

29. G. J. Pickering, D. A. Heatherbell, M. F. Barnes. The Pro. of red.-Alc. wine using. GOX-Tre. juice. Part II. Sta. and SO2-Bin.. Am J Enol Vitic, 50(3):299-306 (1999a)

30. G. J. Pickering, D. A. Heatherbell, M. F. Barnes, The Pro. of red.-Alc. wine using. GOX-Tre. juice Part III. Sen. Am J Enol Vitic 50(3):307-16 (1999b)

31. V. Tilloy, A. Cadiére, M. Ehsani, S. Dequin, Mic. Str. To Red. Alc. Lev. In Wine, ALCOHOL LEVEL REDUCTION IN WINE-OENOVITI INTERNATIONAL NETWORK, 29-32 (2013)

32. K. C. Fugelsang, C. G. Edwards, Wine Microbiology Practical Applications and Procedures, Second Edition (Springer Science, 2007)

33. D. R. Kutyna, C. Varela, P. A. Henschke, P. J. Chambers, G. A. Stanley, Mic. App. to Low. Eth Con. in wine, Trends inFoodScience\&Technology, 21: 293-302 (2010)

34. R. Gonzalez, M. Quir'os, P. Morales, Yea. Res. of Sug. By non-Sac. Yeast Spe.: A Pro. And Bar. Exp. App. To Low. Alc. Con. of wines, Trends in Food Science \& Technology 29: 55-61(2013)

35. M. Quirós, V. Rojas, R. Gonzalez, P. Morales, Sel. of non-Sacch. yeast Str. for Red. Alc. Lev. in wine by Sug. Res. International Journal of Food Microbiology 181: 85-91 (2014)

36. D. Abalos, R. Vejarano, A. Morata, C. Gonza'lez, J. A. Sua'rez-Lepe, The use of Fur. as a Met. Inh. for Red.the Alc. Con. of M. Wines, Eur Food Res Technol, 232: 663-669 (2011)

37. T. Modig, G. Liden, M. J. Taherzadeh, Inh. Eff. of Fur. on Alc. Deh., Ald. Deh. and Pir. Deh. Biochem J 363:769-776 (2002)

38. R. Vejarano, A. Morata, I. Loira, M. C. Gonza'lez, J. A. Sua'rez-Lepe, The. Con. about Usa. of Met. Inh. as Pos. Alt. to Red. Alc. Con. of wines from hot are., Eur Food Res Technol, 237:281-290 (2013)

39. G. J. Pickering, Low- and Red. Alc. Wine: A Rev. Journal of Wine Research, Vol. 11, No. 2, pp. 129144 (2000)

40. M. T. Lisanti, A. Gambuti, A. Genovese, P. Piombino, L. Moio, Par. Dea. of Red Wines by Mem. Con. Tec.: Eff. on Sen. Cha. and Vol. Com., Food Bioprocess Technol 6: 2289-2305 (2013)

41. A. Massot, M. Mietton-Peuchot, C. Peuchot, V. Milisic, Nan. and Rev. Osm. in W.Mak., Desalination 231: 283-289 (2008)

42. M. Gil, N. Kontoudakis, S. Estévez, E. GonzálezRoyo, M. Esteruelas, F. Fort, J. M. Canals, F. Zamora, Non Mic. Str. to Red. Alc. in wines, $A L C O H O L$
LEVEL REDUCTION IN WINE - OENOVITI INTERNATIONAL NETWORK, 25-32 (2013)

43. Y. Y. Belisario-Sánchez, A. Taboada-Rodríguez, F. Marín-Iniesta, A. López-Gómez, Dea. wines by SCC Dis.: Phe. Com. and Ant. Act. Mea. by the 1,1-dip.-2pic. Met., 57(15): 6770-6778 (2009)

44. T. Fornari, E. J. Hernández, A. Ruiz-Rodriguez, F. J. Se norans, G. Reglero, Pha. Equ. for the Rem. of Eth. from Alc. Bev. Using Sup. $\mathrm{CO}_{2}$, J. of Supercritical Fluids, 50: 91-96 (2009)

45. E. S. King, H. Heymann, The Eff. of Red. Alc. on the Sen. Pro. and Con. Pre. of Wh. Wine, Journal of Sensory Studies 29: 33-42 (2014)

46. N. Kontoudakis, M. Esteruelas, F. Fort, J. M. Canals, F. Zamora, Use of unr. Gra. Har. Dur. Clu. Thi. as a Met. for Red. Alc. Con. and $\mathrm{pH}$ of wine, Aust. J. Grape Wine Res., 17, 230-238 (2011)

47. F. Gonçalves, R. Ribeiro, L. Neves, T. Lemperle, M. Lança, J. Ricardo da Silva, O. Laureano, Alc. Red. in wine by Nan. Some Com. with Rev. Osm. Tec., ALCOHOL LEVEL REDUCTION IN WINE OENOVITI INTERNATIONAL NETWORK, 64-67 (2013) 